\title{
SCOTTISH LURGI PLANT
}

$\mathrm{O}^{\mathrm{n}}$ NE of the outstanding problems in present-day utilization of coal is that of using economically inferior fuels of high ash and moisture content. A most interesting development in this respect is the project undertaken by the Scottish Gas Board for the building of a gasification plant, costing ultimately some $£ 6,500,000$, to produce, from low-grade opencast coal, town' gas for distribution over long distances.

The process to be used is known as the Lurgi pressure gasification process, and the final capacity will be some 30 million cubic feet of gas a day. The Lurgi process has emanated from Germany, the gas being generated in the first stage of a series of operations by complete gasification of the coal in producers, pressurized to 25 atmospheres, in a continuous stream of oxygen and superheated steam. The gas produced in this way has a calorific value of 300 B.T.U. per cubic ft.

The heat in the crude gas will be used to raise steam in waste-heat boilers. Tar, oils and ammonia in the effluent will be recovered. Benzole, a valuable by-product, will also be recovered from the crude gas. The oxygen required for the process will be obtained from two air-separation plants, which also produce nitrogen. The nitrogen will be used for adjusting the combustion characteristics of the gas at the end of the process stream.

The Lurgi gas contains rather a higher content of carbon monoxide than is desirable for towns' gas purposes. Accordingly, the Lurgi gas will be subjected to a catalytic conversion of the carbon monoxide and water vapour in the gas to carbon dioxide and hydrogen. This reaction is carried out at high temperature and pressure in the presence of an iron oxide catalyst. The carbon dioxide is then washed out in a plant in which this gas and hydrogen sulphide, arising from the sulphur in the coal, are absorbed in a hot solution of potassium carbonate.

In the interim stage of the development, this gas, to the extent of 15 million cu. ft. a day, now having a calorific value of 400 B.T.U. per cu. ft., will be enriched with butane before distribution, thus raising its heating value to within the requirements of the gas grid. The final desulphurization of the gas, in order to meet the Gas Referees' Standards, will be made in pressurized oxide purifiers.

The subsequent development of the process will in. clude an oil hydrogenation enrichment of the gas to a calorific value of 700 B.T.U. per cu. ft., the final dilution to the normal calorific value of 450 B.T.U. per cu. ft. being effected by means of nitrogen from the oxygen plant.

The site of the plant is to be at Westfield in Fife. The plant will be the seventh large-scale plent of this type in the world. It will take five years to complete the construction of the plant and to lay the associated high-pressure and medium-pressure grid mains. These will distribute the gas over an area extending from Angus and Perthghire in the north through Kinross, Fife and Stirlingshire to Lanarkshire and the Lothians.

This undertaking is a bold venture, which has many novel features in comparison with existing practice in gas manufacture. It is timely becavse it may well serve to demonstrate to industrialists the inherent potentialities of coal, and of its better use, at a time when an over-sanguine conversion to oil for heating purposes may be fraught in the future with possible economic dangers. R. J. SARJANT

\section{TEACHING ZOOLOGY IN BRITAIN}

$\mathrm{T}$ HE Association of British Zoologists held its annual meeting in January in the rooms of the Zoological Society of London, and heard a series of papers on "The Natural Resources of the Country and their Value for Teaching and Research". Dr. J. H. Mundie (Freshwater Biological Association), speaking on the freshwater environment as a field of study, outlined the facilities which exist in Britain for studying freshwater ecology. He attached great importance to good ecological teaching in providing a map of the subject as a whole, and thought that present-day teaching is too factually detailed and passive, so that it tends to stifle the speculative and creative abilities of students. These abilities are found mainly in young people, upon whom the future of research largely depends. He thought that aquatic ecological research, which is essentially a field pursuit, is hampered by university regulations, by which postgraduates are obliged to spend most of their time in college. Commenting on applied problems, Dr. Mundie said that these lie mainly in the fields of water supply and water pollution and are, of course, directly related to human activities. He thought that there is a definite limit to satisfactory modification of the environment in the face of expanding industrialism, and that the best hope of securing conditions of reasonable living lies in adjusting the human rather than the environmental situation.

Speaking on the resources of the sea and the shore, Mr. G. M. Spooner (Marine Biological Association, Plymouth) stressed the great wealth and diversity of the British marine fauna, and gave figures showing the number of zoological specimens supplied each year from some of the marine laboratories in the United Kingdom. He also discussed some of the facilities available for research on marine animals, and the use made of them in fields not strictly concerned with marine biology, such as the important work on nerve physiology carried out on cephalopods. The exhibition of marine fauna in aquaria has, in the main, an educational purpose of considerable value. Under the heading of field study he stressed the importance of the intertidal zone, and mentioned that some areas showing interesting ecological conditions were threatened by the requirements of Service departments. He wondered whether in time the Nature Conservancy would not have to take into its care the intertidal zone in Great Britain.

Mr. T. H. Savory (Haberdasher Aske's School, Hampstead) spoke on the value of land invertebrates for teaching. He suggested that many advantages follow if young zoologists, even before they reach the stage of the Ordinary Level of the General 